\title{
O artista contemporâneo e as novas possibilidades de produção da imagem na Fotografia
}

\author{
Fernando do Nascimento Gonçalves
}

\begin{abstract}
Resumo
O presente artigo tem como objetivo pensar as relações entre a comunicação e as artes como forma de problematizar certos aspectos da cultura comunicacional contemporânea, através da análise dos usos da fotografia por artistas plásticos.O uso pouco convencional que esses artistas vêm fazendo de tecnologias como fotografia chama a atenção por possibilitar a expansão das potencialidades plásticas da imagem fotográfica, permitindo sua resignificação e a renovação de suas condições de produção e recepção.
\end{abstract}

Palavras-chave: comunicação, arte, fotografia.

\begin{abstract}
This paper aims to think the retations between commumication and the arts as a way of problematizing certain aspects of contemporary' communicational culture by the analysis of the use made of photograph by visual artists. The uncanny uses of such technolog' by artists dran' atlention to the possibilities of expansion of the plastic polencialities of the photographic image as well as allowing its resignification and the renewing of its conditions of poduction and of reception.
\end{abstract}

Key words: communication, art, photography:

\footnotetext{
- Douror em Comunicação e Cultura pela ECO/UFRJ. Professor da graduação e da pós.graduação da Faculdade de Comunicação Social da Verj. Foi pesquisador visitanie na Tisch School of The Arts, da Universidade de Nova York, em 2002, com recursos do CNPq. Membro do grupo de pesquisa Comunicação, Arte e Cidade (CAC/Uerj).
} 


\section{O artista contemporâneo e as novas possibilidades de produção da imagem na Fotografia}

$O$ presente artigo nasce do interesse em pensar as relações entre a comunicação e as artes como forma de problematizar certos aspectos da cultura comunicacional contemporânea. $O$ interesse pelo tema surge da percepção de que muitos modos de comunicar na atualidade sofrem e, ao mesmo tempo, promovem estereotipias e padronizações que contribuem para o embotamento das sensibilidades, capacidades perceptivas e visões de mundo.

O uso que os artistas vem fazendo de materiais pouco convencionais e de mídias como fotografia, vídeo e as chamadas novas tecnologias chama a atenção por possibilitar arranjos singulares com a técnica e um diálogo inusitado com nossa contemporaneidade. Por meio dessas operações, é possível revisitar a relação que mantemos com a própria técnica, promover uma releitura de discursos e práticas sociais ligados à constituição de nossos modos de vida e criar novas condições de possibilidade para a produção de diferença.

A arte vai nos interessar nesse contexto especialmente pela aventura de caráter estético e subjetivo a que pode dar lugar - onde o estético diz respeito a formas de sensibilidade criadoras e o subjetivo, à produção social de estilos de vida. Como operador discursivo, a arte participa dos processos de produção de sentido, favorecendo, a um só tempo, a investigação sobre as atuais dimensões da experiência comunicativa, particularmente no tocante à produção de imagens e suas narrativas na atualidade.

Ao discutir as produções de artistas visuais que usam a fotografia para realizar seus trabalhos, pretende-se colaborar com um pensamento crítico sobre uma comunicação que cada vez mais se estandardiza e também evidenciar a pertinência da interseção entre comunicação e arte como forma de oxigenar e expandir os usos tradicionais feitos pelas tecnologias de comunicação, singularizando-os.

No presente artigo discutiremos alguns dos trabalhos de dois artistas brasileiros contemporâneos - Rosângela Rennó e Alex Fleming - que fazem da fotografia um suporte importante para suas criações. Apesar de seus trabalhos não se resumirem à interação com a imagem fotográfica, é muito curioso observar a natureza dos usos feitos por eles dessa tecnologia. Esses usos caracterizam-se basicamente, como veremos, não apenas pelo caráter de "expansão" de suas possibilidades expressivas, mas também pela reconfiguração das estruturas que presidem a produção e recepção dos signos visuais.

Abordaremos a questão apoiados nas análises de Arlindo Machado sobre a produção de imagens técnicas e dos processos criativos com tecnologia, que concebem a técnica e os meios de comunicação como "máquinas semióticas" (Machado, 2001, p. 41), elementos que não apenas 
produzem registros do real e possibilitam a troca de mensagens, mas que seriam elas próprias produtoras de sentido e de bens simbólicos que interferem em nossos sistemas de vida e de pensamento, em nossa capacidade imaginativa e em nossas formas de percepção do mundo'.

Antes, porém, de partir para as análises sobre os usos feitos por esses artistas, cabe uma discussão preliminar sobre as mudanças nas concepções de arte, mudanças essas responsáveis pelo surgimento de novas estratégias criativas e novas linguagens.

Se hoje se discute na arte noções como as de obra, de suportes e linguagens, além, é claro, a da própria arte, é porque sem dúvida alteraram-se as concepções que temos da experiência artística e suas formas de produção, difusão e fruição. O que hoje conhecemos como crise da arte, é na verdade, um processo de transformação que se inicia ainda no século XIX e que se acelera com uma longa experiência de rompimentos e experimentações iniciadas com o modernismo e com as vanguardas artísticas européias no iníciop do século XX em seus distintos movimentos - dadaísmo, cubismo, surrealismo, futurismo, entre outros.

Essas experimentações podem ser vistas já como estratégias de uma arte dotada da consciência de uma certa descontinuidade, que vai romper com os cânones da arte clássica através da aposta na crise dos modelos de representação. Esse rompimento iria mais tarde abrir espaço para uma outra crise, dessa vez na própria arte e que lhe seria fatal.

Como afirma Danto (2003), na segunda metade do século XX, as grandes narrativas sobre o mundo, o homem e a socicdade definitivamente se esfacelam e a história deixa de ser centrada num relato oficial. A década de 1970 é considerada por Danto como marco de percepção dessas crises. A chamada "morte da arte" significa exatamente o término de uma certo modo de se pensar a arte e de produzi-la. Por isso, certamente, o que morre não é a arte em si, mas sua identificação com um relato oficial e uma experiência de arte que produz objetos auráticos concebidos para serem contemplados.

É assim que vemos surgir dessa crise uma arte - "depois do fim da arte" (Danto, 2003) - que vai preferir formas lúdicas, disjuntivas, ecléticas e fragmentadas, que permitem uma mistura e uma reapropriação de estilos, discutindo e não mais recusando as questões de uma sociedade e de uma cultura cada vez mais mediatizadas.

Nesse sentido, o artista contemporâneo trabalha não mais com desejo de rompimentos ou superações, mas com o de deslocamento e resignificação. Daí poder-se pensar a arte contemporânea como estando mais para o código (subjetivo) do que para a linguagem (objetivo) e evocando mais a idéia de rede e de constelação (dispersão) do que de estrutura.

Partindo dessa premissa, poderíamos afirmar que a arte, em sua condição contemporânea, não se interessaria mais em produzir saberes ou 
sagrados, ou discutir a própria arte, como no modernismo. Antes, vai preferir articular questões ligadas às experiências do nosso tempo.e do cotidiano. Daí a grande liberdade para o uso e apropriação de desde objetos banais às telas do computador, aos hipersistemas de redes telemáticas ou mesmo a biotecnologia como ferramentas para fazer arte feita a partir da articulação de distintos elementos que, cruzados entre si, vão constituir uma vasta rede sígnica.

Concebida dessa forma, a arte funcionaria como uma engrenagem, uma máquina produtora de novas sensibilidades. É esta máquina que realiza, segundo Caiafa, "um trabalho criador com as formas expressivas e abre brechas nas subjetividades padronizadas, fazendo surgir singularidades" (Caiafa, 2000:66). Esse trabalho criador é precisamente um exemplo do que Guattari (1993: 134-135) chamou de processos de singularização, processos que surgem desse poder da arte de produzir rupturas nas significações dominantes e de sua capacidade de operar também transformações na própria subjetividade, quando os segmentos semióticos que a constituem passam a formar novos campos significacionais.

Quando proponho pensar a relação entre os campos da comunicação e da arte, estou precisamente propondo pensar a arte como um dos elementos singularizadores das experiências comunicativas, através da instauração de uma multiplicidade no interior das instâncias expressivas. Essa multiplicidade estaria fundada precisamente na possibilidade permanente de mutação dessas instâncias e seus agenciamentos, que se tornariam, assim, capazes de engendrar novas referências para a produção de sentido. É nesse sentido vejo a contribuição da arte contemporânea em sua interseção com a comunicação.

Os usos artísticos de distintos elementos do cotidiano têm promovido uma intensa resignifiçação de suas finalidades, capaz de instaurar com eles uma relação diferenciada, inclusive com os meios de comunicação, embora certamente de forma minoritária. Esse trabalho de resignificação consiste exatamente na apropriação e na resignificação de objetos, imagens, discursos, textos, do corpo, além de tecnologias de comunicação como fotografia, cinema, vídeo e, atualmente, o computador, a Internet, além das biotecnologias.

Uma das tecnologias mais utilizadas atualmente na arte contemporânea é a fotografia. E não por acaso. Para Stéphane Huchet, "a fotografia é um veículo cujo impacto ainda é forte porque abarca consigo um estatuto ambíguo de objeto e de mediação ao mesmo tempo técnica e cultural" (in: Santos, 2004, p. 14). Seria por meio dessa ambigüidade que a fotografia permitiria aos artistas construírem circunstâncias singulares de percepção, ao produzirem um estranhamento da imagem e pela imagem.

É que, como afirma Sontag, a fotografia seria um poderoso instrumento de distanciamento e de despersonalização de nossa relação com o mundo, na 
medida em que a câmera faria com que as coisas "exóticas" parecessem próximas e as "familiares", estranhas e distantes. A fotografia, para Sontag, não apenas reproduziria o real, mas também permitiria sua reciclagem. A fotografia operaria, assim, como um elemento primordial na constituição do imaginário moderno e deveria ser observada através das operações capazes de engendrar o visível possível na atualidade. Dentro dessa mesma lógica, a fotografia, como afirma Philippe Dubois (1994), pode, finalmente, não ser apenas instrumento de reprodução documentária, mas também pensamento.

É nesse aspecto de pensamento que tomaremos nossas análises sobre o uso que artistas fazem hoje da fotografia para a produção de outras imagens. Para os artistas contemporâneos, a imagem fotográfica é tida como elemento maleável, escultural sobre cujo plano eles inscreveriam seus trabalhos. Ela não seria mais trabalho em si ou seu fim último. mas a base para a criação de um corpo de obra. É que, como afirma Virgínia Araújo, a nova produção imagética "deixa de ter relações com a realidade imediata, não pertence mais à ordem das aparências, mas aponta para diferentes possibilidades de suscitar o estranhamento em nossos sentidos" (in: Santos, 2004, p. 80).

A imagem folográfica no contexto da arte contemporânea já não seria mais vista (apenas) como um objeto indicial que fala do mundo ou que o representa. Antes, seria, como afirma Régis Durand, um elemento que "anula a duplicação" do composto referente-imagem (apud Gattinoni e Vigouroux, 2002, p. 49), que os isola para então recombiná-los de outra forma. dandolhes outro sentido.

É assim que a "arte como fotografia" - para usar uma expressão cunhada por Walter Benjamin (1993)² - permite desvendar novos recortes sobre a realidade e outras possibilidades de constituição do olhar. Consequientemente, essa operação nos leva a todo um conjunto de novas imagens e de novas estratégias de produção de imagens. que não desejam mais necessariamente representar, mas (re)apresentar. Mostrar de novo.

Um das marcas dessa "reapresentação", como veremos, é o interesse dos artistas em criar novas referências para essas imagens, ligando-as a outros universos de sentido. Na verdade, o que eles fazem é inserir as imagens numa grande rede sígnica. onde o sentido das imagens é constantemente recriado.

E a cena artística contemporânea brasileira tem sido pródiga em oferecer exemplos de criadores que se apropriam da fotografia para fazer-nos tomar imagens e suas narrativas do mundo, estranhá-Jas e reprocessá-las. Com isso, as imagens ganham novos sentidos ao serem cruzadas com temas sociais, políticos. filosóficos, tornando-a, de fato. parte de uma estratégia discursiva. 
Um desses artistas é Rosângela Rennó, arquiteta de formação e artista plástica mineira radicada no Rio desde o final dos anos 80 , que vem merecendo atenção pela maneira desconcertante com que trata a dimensão social do anonimato na fotografia.

A exemplo de diferentes artistas brasileiros que utilizam a fotografia como base para suas criações, as produções de Rennó parecem oferecer material para interessantes questionamentos, tanto no campo da arte, quanto no da comunicação e também em relação aos processos de produção de sentido nos discursos e práticas sociais e aos modos de representação e percepção do presente e de construção da subjetividade.

Duas das temáticas caras ao trabalho da artista e sobre as quais vamos nos debruçar aqui são: $o$ anonimato e o ciclo de vida da imagem fotográfica. Ambas remetem a uma questão mais ampla que é a da produção da memória social, mais particularmente, aos modos de se fazer lembrar e esquecer em nossa sociedade.

Curiosamente, o que vai interessar à artista não será nem o ato fotográfico nem tampouco seu resultado, mas as leituras que se podeḿ fazer dos modos de organização do olhar e de representação do outro, não como singularidade, mas como "mesmo". Ou seja, os mecanismos pelos quais uma sociedade ordena as percepções do outro através de imagens e como esse processo se insere em determinados modelos simbólicos com fins de ordenação social ou mesmo de exclusão.

190 Rennó vai ver a fotografia como algo que poderíamos chamar de "tecnologia social de arquivo" e, portanto, como discurso e prática social. Ao partir da percepção da imagem como ferramenta de desatenção na atualidade - pela indiferenciação e pelo excesso de imagens que produz seus trabalhos levantam exatamente a questão da fotografia como um mecanismo institucional que parece em muitos momentos "dissolver registro, memória e imagem”, como afirma Felipe Chaimovich (1998).

Daí o uso freqüente da apropriação para a produção de suas obras. Curiosamente, a artista não produz suas próprias imagens do outro, ela trabalha com negativos de fotos $3 \times 4$ de pessoas comuns, imagens de álbuns de família vendidos nos mercados públicos do Rio e de todo o mundo ou de jornais, dos quais extrai textos que fazem referências a fotografias, todas já sem utilidade ou valor e quase sempre encontradas em arquivos de ateliers fotográficos populares e que ela vai então reinserir no plano simbólico.

Colecionando negativos e imagens aos milhares, a artista os resgata de um processo de esquecimento e os retrabalha, não apenas transformandoos em obras de arte, mas também num interessante canal de crítica, que questiona o excesso de informação imagética, seu acúmulo e seu posterior descartamento.

A figura do descarte em Rennó é um dos aspectos mais explorados em seus trabalhos, como modo de abordar esse fenômeno que ela chamou de 
"desmemorialização" pela imagem. Interessa à artista discutir o ciclo de vida de uma imagem, o processo de descolamento do referente em relação à imagem e sua posterior transformação em objeto (tanto de arte como de arquivo).

Assim é que a artista não vai lidar com pessoas, mas com tipos. Ao invés de tentar identificá-las, vai evidenciar o apagamento das diferenças produzido pelas tecnologias de arquivo.

Um dos trabalhos que permite ilustrar sua preocupação com a desmemorialização é "A mulher que perdeu a memória" (foto l). Parte da série "Pequena ecologia da imagem", o trabalho se constitui da apropriação da fotografia em preto e branco, sem foco, de uma mulher idosa que parece sorrir. Quem seria aquela mulher, cuja imagem descartada teria sido encontrada ao acaso? O desfocamento da foto impede totalmente o reconhecimento de sua identidade. Mas, na verdade, em que medida importa sabê-lo? Ao considerar essas perguntas, a apropriação feita por Rennó ganha, por exemplo, uma dimensão questionadora do valor do idoso na sociedade, que privilegia os "corpos produtivos" e descarta os demais. Ou seja, o que a sociedade atualiza é uma memória que realimenta seus pressupostos.

Porém, igualmente interessantes são suas experimentações artísticas com a imagem fotográfica. Rennó produz instalações com imensas ampliações dessas imagens e de negativos, ao mesmo tempo em que as altera e esculpe por meio de processos químicos e de digitalização no computador, ressaltando a idéia da possibilidade de manipulação da realidade inerente às tecnologias de reprodução. Como já dissemos, o que lhe interessa não é o ato fotográfico em si, mas o alongamento de sua qualidade processual e as potencialidades plásticas que ela propicia. O que lhe toca, portanto, é menos a imagem e mais as formas híbridas que o objeto fotográfico pode assumir. É quando em suas apropriações a imagem vai ganhar um estatuto escultural.

Tomando para si as possibilidades dessas experiências com a fotografia, vemos nas instalações de Rennó, por exemplo, um interesse em mesclar imagens do início do século com suportes e materiais contemporâneos, como a fotografia digital (Série Vermelha, 1996-2000), ou com imagens projetdas e cilindros com topos luminosos com lâmpadas halógenas e caixas de luz alimentadas por transformadores (Humorais, 1993). O resultado: grandes imagens que não podem ser reproduzidas com papel fotográfico. Porém. segundo a artista, mais interessante que os efeitos estéticos produzidos pelo tratamento pós-fotográfico obtido com esses materiais e equipamentos é a mudança de significação obtida por essas velhas imagens em contato com esses novos meios (Rennó in Herkenhoff, 1998, p. 179).

A série Vermelha (foto 2), por exemplo, mostra imagens de adultos e crianças desconhecidos do início do século XX em uniformes militares. As imagens foram retiradas de álbuns vendidos em mercados públicos ou dados à artista e foram tratadas digitalmente de forma a ganhar uma espessa camada 
vermelha, que recobre mas não apaga totalmente a imagem. O resultado é uma imagem vermelha que guarda um "segredo" e que, além de provocar o olhar, se transforma num curioso olhar sobre a guerra, a violência, e de certa forma, sobre sua histórica institucionalização.

Em Humorais (foto3), Rennó trabalha com as imagens de cinco tipos humanos, quatro dos quais baseados nos tipos descritos por Galeno - médico grego que explicava a saúde por quatro tipos de humores (sanguíneo, bilioso, fleumático e melancólico). A esses quatro tipos, a artista acrescenta o homem contemporâneo, segundo Paulo Herkenhoff $(1998,154)$, "um tipo violado pela epidemia de imagens". Depois, vai trabalhar com os cinco tipos a partir de imagens de homens anônimos ampliadas de retratos $3 \times 4$ e projetadas contra uma tela feita em acrílico leitoso e bojudo que produz uma distorção. As imagens dos rostos são apoiadas em cinco cilindros ou caixas imersas numa penumbra, o que thes acentua o aspecto espectral.

Em cada caixa acompanha um texto que funciona como uma espécie de definição de cada um dos cinco tipos de temperamentos, só que com a particularidade de que os textos são trechos extraídos do Código Penal Brasileiro. Assim, cada imagem (e cada anônimo) ganha um título que remete a um tipo de crime atribuído a cada tipo de humor por suas características. Com isso, temos formado um jogo entre o código dos humores galenos com o código penal através do confronto entre a tipificação de crimes e os retratos dos anônimos. A fotografia, que ganham espaço também na tipologias 192 fisionômicas da criminologia positivista, entra aí num jogo de conotação que explicita o caráter arbitrário dessas tipificações, numa clara referência ao fato de se antes a foto era simplesmente registro e evidência do real, agora vai se tornar molde de construção do real, do esquecimento, da indiferenciação e exclusão.

Esse o papel do anonimato no trabalho da artista. Algumas de suas produções mostram "como os mecanismos institucionais parecem produzir uma dissolução entre registro, memória e imagem", como afirma Chaimovich (in Herkenhoff, 1998:87). No lugar de comunicação, inexpressão, perda de significado. Assim é que, ao invés de lidar com pessoas, a artista vai trabalhar com tipos. Ao invés de identificá-las, vai retrabalhar o apagamento das diferenças produzido pelos meios oficiais de memória e os efeitos da massificação da produção da imagem, que banalizam e anulam as diferenças na vida social.

Do ponto de vista das estratégias de produção de imagens, percebemos que nessas operações a fotografia parece ser assumida em sua materialidade precária e inserida num projeto visual que busca não mais representar, mas criar novas imagens, novas narrativas que permitam produzir significados dinâmicos com os objetos e o cotidiano. Ao retirar a imagem de seu contexto habitual e cruzando-as com outras referências, os artistas destróem seus 
clichês e rompem com suas associações estereotipadas, dotando-lhes de uma faceta insólita e de uma densidade perceptiva que nos obriga a reaprender a ler as imagens.

Esse efeito de alteração está muito próximo do produto da técnica de "apropriação", que é uma das características daquilo que Craig Owens chamou de "alegoria". A alegoria seria um elemento estético que permite que um texto seja "lido através de um outro texto", operando uma "rescritura de um texto primário em termos de seu significado figural" (Owens, 1992: 205). Owens explica que a apropriação pode também ser de uma imagem. Nesse caso, consistiria não em "inventar imagens" e sim, em "confiscá-las", através do que, estas "se tornariam outra coisa".

Trata-se não de restaurar um significado original que havia sido perdido ou obscurecido. Antes, o procedimento alegórico adicionaria um outro significado à imagem. Mas essa adição, complementa Owens, só ocorre para uma substituição, que suplanta o significado anterior. A alegoria tem na "apropriação" sua principal ligação com a arte contemporânea. Através dela, muitos artistas geram imagens através da reprodução de outras imagens que, frequientemente, consistem elas próprias uma forma de reprodução -. como a fotografia.

Ao trabalhar, portanto, com os resíduos de presenças dentro de uma memória descartável e descartada, a artista chamaria a atenção para o fato de que no caso da fotografia o esquecimento não coincide exclusivamente com o ato de não lembrar. Antes, remeteria ao ato de lembrar apoiado em um arquivo de memória que pode fazer esquecer ou negar a singularidade pela própria indiferenciação na imagem. Os trabalhos da artista parecem de fato demonstrar como a saturação da imagem fotográfica é capaz de criar uma opacidade que apaga a consciência de si em relação às regras e jogos sociais. na intenção de registrar os fatos do presente.

Interessante observar como, em Rennó, o debruçar-se sobre a profusão de imagens e sobre uma memória produzida e descartável possibilita também repensar jogos e regras de poder e exclusão na sociedade contemporânea. Fotografias "sem valor" encontradas em jornais, obituários e de identificação criminal têm assim o poder de funcionar, em suas obras, como fotografias "não-fotográficas". Seu trabalho demonstra precisamente como é possível retrabalhar essas imagens e fazer delas outra coisa.

Porém, as questões da identidade e da subjetividade remetem à outra não menos complexa. Curiosamente. a folografia sempre foi um processo regulador do corpo e de suas formas de (re)presentação. processo esse que vem a ser uma dos modos mais eficazes de regular também a experiência social, como já observara Foucault.

A noção do corpo é histórica, nascida da cultura. Sua imagem é a de um artifício que deve estar preparado para o espaço social. na medida em que 
"sustenta como matéria a produção de processos de identificação a partir das evidentes marcas visuais que expõem a identidade do sujeito consigo próprio com o grupo do qual participa e pelo qual quer ser acolhido e reconhecido (...)" (Tucherman, 1999: 106). É provavelmente por isso que Sidonie Smith acredita que "a naturalização do corpo pode ser um terreno enganoso, talvez o espaço do estranho e não 'do familiar', pois sendo uma construção cultural e, portanto, política, a evidência do corpo pode apenas oferecer um aparente continuum de identidade estabilizada" (Smith,1994:267).

Por isso mesmo, o corpo tem sido recorrentemente discutido, de forma crítica, nas artes, desde as vanguardas modernistas do início do século $\mathrm{XX}$, mas também na atualidade. No Brasil, vários são os artistas que têm se ocupado do corpo e dos investimentos de que este tem sido alvo em nossa sociedade. No contexto chama a atenção, além dos trabalhos de Rosângela Rennó, as obras do artista plástico paulista Alex Fleming, atualmente radicado na Alemanha desde os anos 90.

Coincidentemente, Fleming também iniciou na arquitetura (FAU/USP) nos anos 70, período em que começou a fazer experimentações com imagens (filmes super-oito, arte-xerox, fotografias e gravuras) no âmbito da arte conceitual $^{3}$, então em voga nos Estados Unidos e também aqui no Brasil. Lidando desde o começo com distintas linguagens, Flemming - que chama a si mesmo de pintor -, tem sido pródigo na produção de instalações onde a fotografia tem surgido como meio para problematizações do político, da 194 memória, do mítico e da identidade, por meio da discussão do corpo como espaço de significação social.

Nos anos 80 , realizou séries fotográficas feitas a partir de imagens colhidas em revistas que denunciavam a tortura na América Latina e do registro feito por ele próprio de pessoas anônimas no exercício de suas profissões. Ai, a presença do corpo é evidente, mas não é ainda seu foco, o que viria a acontecer mais tarde. Ainda nos anos 80 , em suas pesquisas, Flemming vai realizar inúmeras séries fotográficas sobre o corpo e suas metáforas, que se caracterizam pela produção de imagens de partes do corpo, que se repetem, combinam e justapõe, no exercício de técnicas muito próprias das artes plásticas, a apropriação e a colagem, como “Torsos", de 1983.

Mas o artista se notabilizou ao criar, nos anos 90, uma longa de série intitulada Body Builders (Modeladores do Corpo), onde retrata corpos jovens, esbeltos e anônimos, sobre os quais desenhou, com auxílio de computação gráfica, mapas de regiões de conflito no mundo, como Iraque, Israel e México, áreas que foram e são de interesse neocolonialista de países ricos.

As imagens resultantes, "torsos gregos da pós-modernidade" (fotos 4, 5 e 6), como definiu Ana Mae (2002, p. 13), remetem às ritualizações do corpo individual atravessado pelas lutas territoriais do passado e do presente e que mapeiam diferenças culturais. Em algumas imagens, o artista articulou 
a política à questão da memória, ao inscrever em alguns desses corpos textos bíblicos que já falavam de guerras e perseguições por razões semelhantes às das que acontecem hoje e que ele então denuncia.

Seguindo suas explorações do corpo, Fleming preparou em 1998 uma instalação com fctos de identidade do tipo $3 \times 4$ na estação Sumaré do metrô de São Paulo (foto 7). As imagens eram de anônimos trabalhadas no computador e às quais ele adicionou letras coloridas com tipologia de máquina de escrever, que, na verdade, formavam palavras e trechos de poemas de autores brasileiros de diferentes momenıos da história de nossa literatura, do século XVI aos dias atuais. As imagens foram ampliadas e expostas na estação do metrô para serem vistas pelos passantes, eles próprios anônimos. A idéia era confrontá-los com sua própria condição de anonimato na grande metrópole, onde é apagada sua condição de "outro". O jogo de duplicação reacende, mesmo que de forma precária e efêmera, a singularidade de não deixar de ser "outro" mesmo na multidão.

Em 2004, Fleming expõe uma série de novas imagens de anônimos na Pinacoteca do Estado de São Paulo ("Alex Fleming - Fotografias") e no Centro Cultural do Banco do Brasil de Brasília ("Identidade \& Conflito") para o centro do poder "poder ver", segundo o artista. Só que dessa vez, as fotografias não são de identidade: ao contrário. não mostram os rostos das pessoas flagradas por ele em situações banais do cotidiano. em cidades do Brasil (Paranaguá e São Paulo). Bangkok (Tailândia) e Berlin e Dresden (Alemanha). fazendo compras na feira, tomando drinks num bar, os mesmo posando para o fotógrafo (fotos 8,9 e 10)

$O$ artista recriou as fotos através da colorização dos negativos no computador, imprimindo-lhes um forte contraste. As imagens que daí resultam foram chamadas de "Epifanias cromáticas" no texto de apresentação da exposição. O curador da mostra paulistana acrescenta comparando com o trabalho anterior do artista (no Metrô de São Paulo): "Se anteriormente a escrita se fez presente para re-significar as imagens e dar-lhes novas camadas de interpretação, nesta série o artista se vale estritamente da apresentação do elemento pictórico em suas fotografias".

A mesclagem de distintas linguagens (no caso. da fotografia com a da pintura, marca do trabalho do artista) é uma das estratégias que artistas contemporâneos usam - herança das vanguardas artísticas européias do início do século XX e dos artistas americanos do pós-guerra - para produzir colagens visuais que expandem as possibilidades expressivas dessas imagens por inseri-las muma complexa rede narrativa resultante do cruzamento de distintas referências que a um só tempo conotam e denotam.

De fato, essas imagens, emborat apoiadas na fotografia. não são mais simples fotografias: são híbridos manipuladas pelo artista e transformadas 
em esculturas que dialogam e ganham sentido com o espaço da exposição (instalações). São "fotografias-escultura", como observa Dominique Baque (1998:176), uma forma imagética típica das intervenções artísticas onde o objeto fotográfico parece reivindicar uma outra materialidade, a partir da produção de fotografias de fotografias, de performances, de imagens autobiográficas e ambientes-escultura organizados para serem fotografados.

Nesse sentido, assim como em cada época da História, a condição contemporânea da produção de imagens artísticas guarda forte ligação com a cultura comunicacional de nosso tempo, e, sobretudo, talvez, com a construção social de modos de existência e de subjetivação implicados nessas produções de imagens.

Trabalhos de artistas como Rosângela Rennó e Alex Fleming são, portanto, apenas alguns exemplos de experimentações que atestam a possibilidade de se pensar não apenas usos diferenciados da imagem fotográfica, mas também modos de problematizar à produção de imagens em nossa sociedade. Ao escolherem a identidade, o anonimato e o corpo como questões a serem discutidas em seus trabalhos, esses e outros artistas parecem ser capazes de levantar, através de sua arte, questiốes relevantes que urgem ser pensadas em nossa sociedade e que, ao mesimo tempo, estão a exigir de nós novos referenciais e modos de intervenção.

Se o mundo atual é marcado pela incerteza, pela fragmentação; pela acumulação e pela colagem e justaposição de tempós, espaços e experiências: a arte contemporânea deixa para trás uma certa "coerência sistêmica" característica, em alguns momentos, da modernidade, e vai produzir imagens em permanente estado de descontinuidade, que nós permitem conviver com as imagens de nosso tempo - em um duplo sentido -, reconhecê-las e refletir a partir delas sobre nossa própria condição contemporânea.

Se como afirmou Flusser, as imagens técnicas são difíceis de serem . decifradas justamente porque elas parecem não precisar ser decifradas, os ; artistas vêm nos mostrar o contrário. Nos oferecem interessantes lições no sentido de nos fazer prestar mais atenção nelas, percebê-las em sua complexidade, para enfim resgatar em nós o hábito de lê-las e de exercitar a velha e boa capacidade de imaginar.

\section{Notas}

${ }^{1}$ Essa percepção segue na esteira do pensamento de Vilém Flusser, para quem as imagens técnicas seriam apenas falsamente objetivas e seriam dificilmente decifráveis pela razão curiosa de que aparentemente não necessitam ser decifradas. Na verdade, Flusser, ao discutir esse aspecto, vai afirmar que: "A aparente objetividade das imagens técnicas é ilusória, pois na 
realidade são tão simbólicas quanto o são todas as imagens. Devem ser decifradas por quem deseja captar-lhes o significado. Com efeito, são elas sí mbolos extremamente abstratos: codificam textos em imagens, são metacódigos de textos" (1985, p.10).

${ }^{2}$ Em a "Pequena História da Fotografia", Benjamin faz uma diferença entre a "arte como fotografia" e "fotografia como arte". Primeira teria na fotografia uma das formas de expressão da arte. A segunda diz respeito ao uso comercial da fotografia, que the conferiria um aspecto "espetacular", produzido para seduzir e encantar, o termo "arte" aí com conotação pejorativa e irônica.

${ }^{3} \mathrm{~A}$ arte conceitual foi um movimento de arte de fins dos anos 60 e começo dos 70 que representou um processo de reflexão sobre a arte e o fazer artístico. A arte conceitual procurou "desestetizar" a arte num momento de freqüentes questionamentos sobre o significado e a função da arte frente à sua crescente mercantilização, ficando conhecida como "arte de idéias". No Brasil, o Museu de Arte Contemporânea da USP, já nos anos 70, foi um dos primeiros a abrigar mostras e exibições desse tipo de expressão artística, como demonstrou Cristina Freire (1999).

\section{Referências}

ARAÚJO, Virgínia Gil. Realidades imaginárias na fotografia: a artificialidade, os espectros e as ruínas da realidade. In: SANTOS, Alexandre e SANTOS, Maria Ivone (Org.). A fotografia nos processos artísticos contemporâneos. Porto Alegre: UFRGS, 2004.

BARBOSA, Ana Mae (Org.) Alex Fleming. São Paulo: Edusp, 2002.

BAQUÉ, Dominique. La Photographie plasticienne. Paris: Éditions du Regard, 1998.

BENJAMIN, Walter. Magia e Técnica, Arte e Política. Obras Escolhidas, vol 1. São Paulo: Brasiliense, 1993.

CAIAFA, Janice. Nosso Século XXI: notas sobre Arte, Técnica e Poderes. Rio de Janeiro: Relume-Dumará, 2000.

DANTO, Arthur. Después del fin del arte. Buenos Aires: Paidós, 2003.

DUBOIS, Phillipe. O ato fotográfico. $4^{\mathrm{a}}$ ed. Campinas: Papirus, 1993.

FLUSSER, Vilém. Filosofia da caixa preta. São Paulo: Hucitec, 1985.

GUATTARI, Félix. Caosmose. Rio de Janeiro: Ed. 34, 1992.

HERKENHOFF, Paulo. Rennó ou a beleza e o dulçor do presente. In: Rosângela Rennó. São Paulo: Edusp, 1998.

HUCHET, Stéphane. Tal qual, a fotografia. In: SANTOS, Alexandre e SANTOS, Maria Ivone (Org.). A fotografia nos processos artísticos contemporâneos. Porto Alegre: UFRGS, 2004.

GATTINONI, Christian et VIGOUROUX, Yannick. La photographie contemporaine. Paris: Éditions Scala, 2002. 
MACHADO, Arlindo. O quarto iconoclasto e outros ensaios hereges. Rio de Janeiro: Rios Ambiciosos, 2001.

OWENS, Craig. Beyond Recognition: Representation, Power and Culture.

Berkeley: UCLA Press, 1992.

SONTAG, Susan. Ensaios sobre fotografia. Rio de Janeiro: Arbor, 1981.

SMITH, Sidonie. Identity's Body. In: ASHLEY, Kathleen (Org.) Autobiography and Postmodernism. Anherst: University of Massachusetts, 1994.

TUCHERMAN, Ieda. Breve história do corpo e de seus monstros. Lisboa:

Passagens, 1999.

Body Builders

198

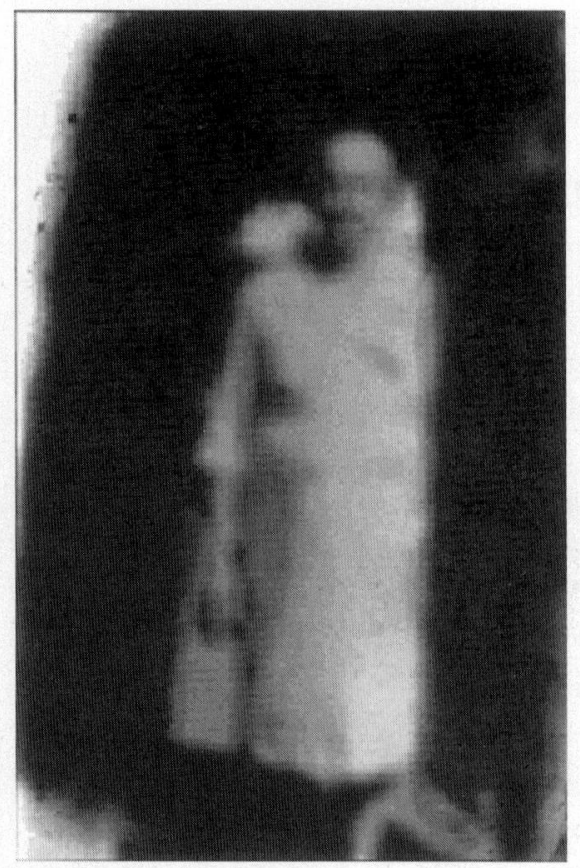

Foto 1-A mulher que perdeu a memória 


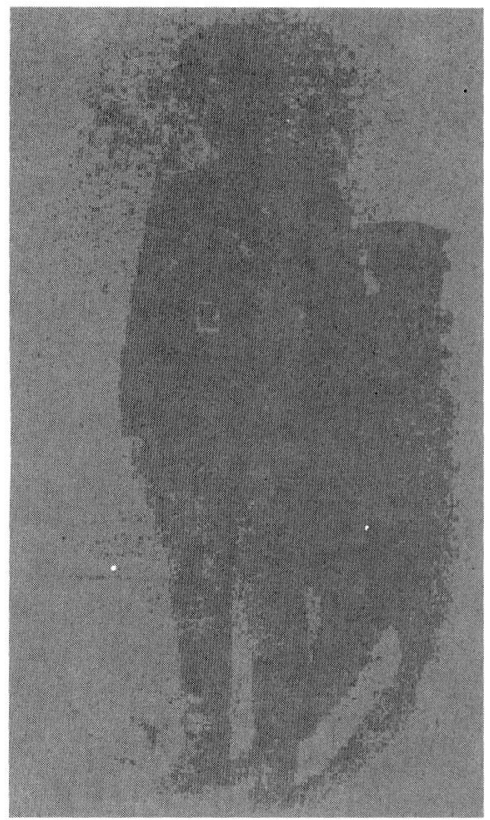

Foto 2 -Série Vermelha
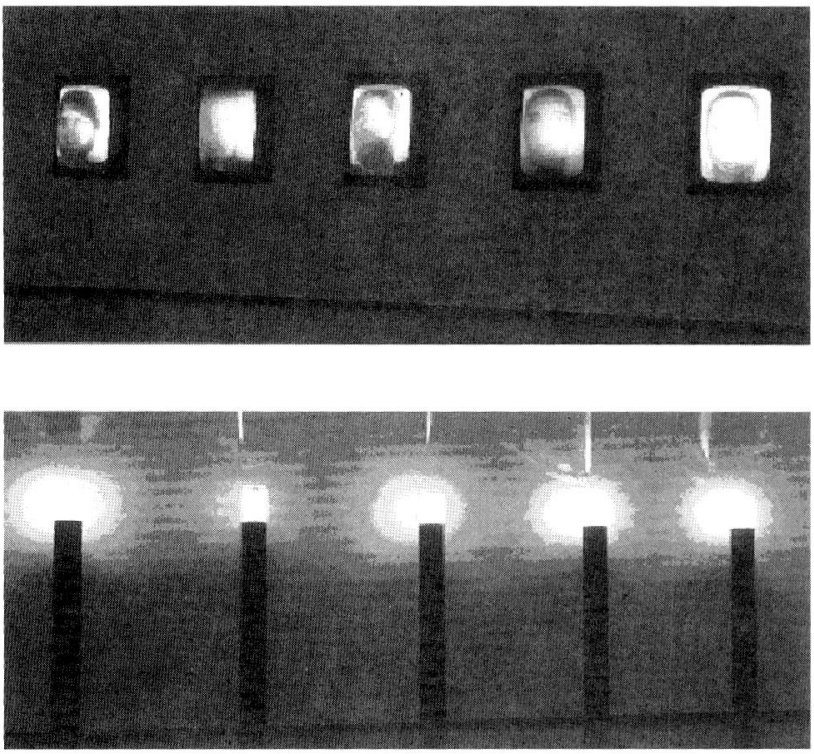

Foto 3 - Humorais 


\section{Body Builders}

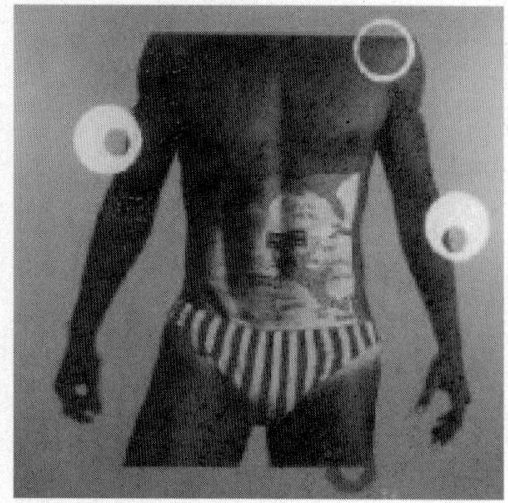

Foto 4

200

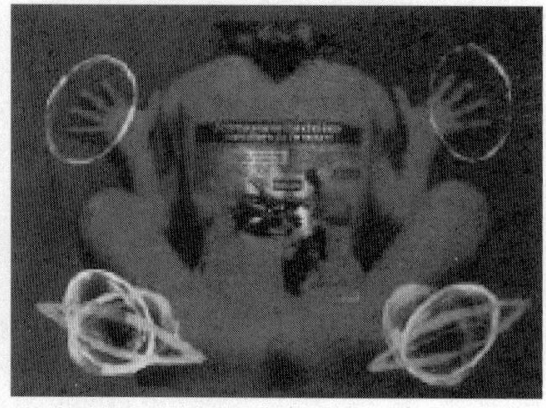

Foto5

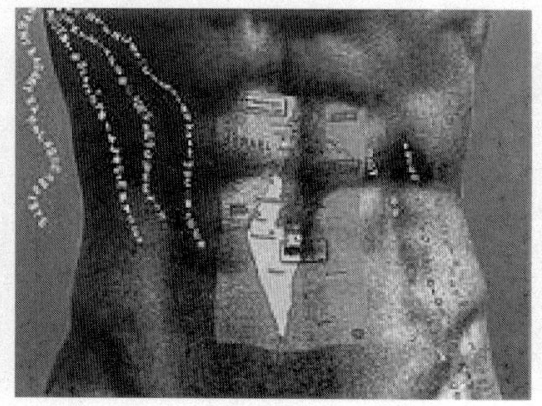

Foto6 
Alex Fleming: Fotografias

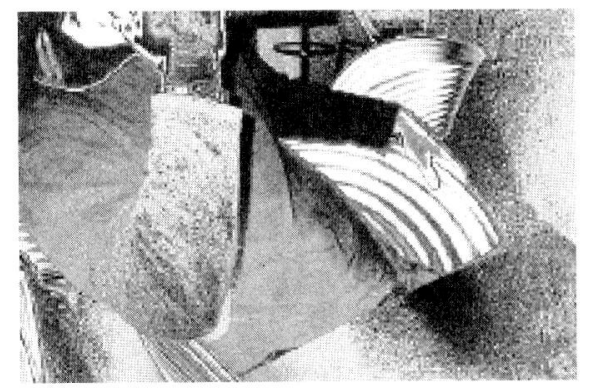

Foto 8

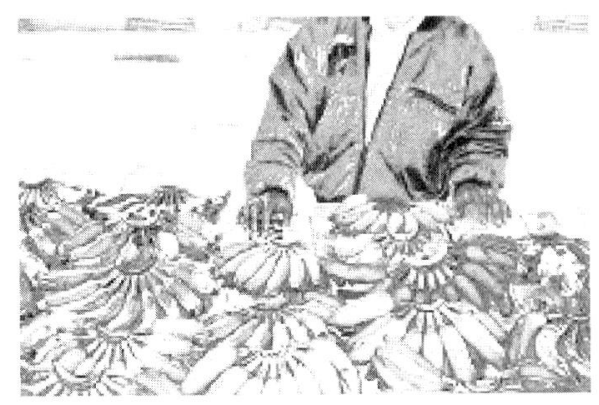

Foto 9

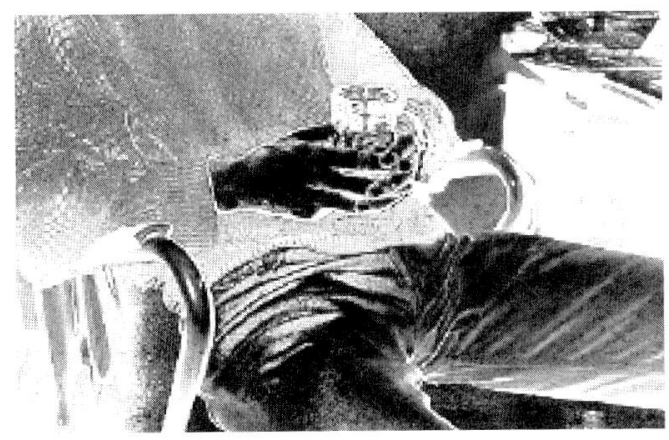

Foto 10 
202 